\title{
Localized Breast Amyloidosis
}

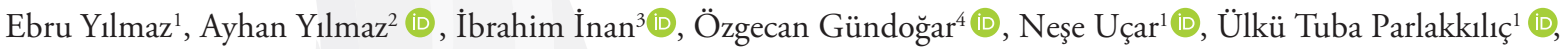 \\ Ahmet Aslan ${ }^{\text {(D) }}$, Elife Kımıloğlu ${ }^{4}$ (D) \\ ${ }^{1}$ Department of Radiology, Gaziosmanpaşa Taksim Training and Research Hospital, İstanbul, Turkey \\ ${ }^{2}$ Department Radiology, University of İstinye Hospital, İstanbul, Turkey \\ ${ }^{3}$ Department of Radiology, Adıyaman University Hospital, İstanbul, Turkey \\ ${ }^{4}$ Department of Pathology, Gaziosmanpaşa Taksim Training and Research Hospital, İstanbul, Turkey \\ ${ }^{5}$ Department of Radiology, Medeniyet University Hospital, İstanbul, Turkey
}

\begin{abstract}
Localized amyloidosis in the breast is a very rare disease and may mimic malignant lesions. A 60-year-old woman who had a history of breastconserving surgery presents with a new a well-defined oval opacity accompanied by many round tight clustered micro- and macrocalcifications on mammograms. It could not be visualized sonographically due to the intense posterior acoustic shadowing of the fat necrosis areas and contrast enhancement was not detected in this area on the dynamic contrast enhanced magnetic resonance images. At pathological examination breast amyloidosis was detected. Amyloidosis of the breast is a rare disease, but it can mimic malignancy and should be included in the differential diagnosis.
\end{abstract}

Keywords: Amyloidosis, localized amyloidosis, breast carcinoma

Cite this article as: Yılmaz E, Yılmaz A, İnan İ, Gündoğar Ö, Uçar N, Parlakkılıç ÜT, Aslan A, Kımıloğlu E. Localized Breast Amyloidosis. Localized Breast Amyloidosis. Eur J Breast Health 2018; 15(1): 63-66.

\section{Introduction}

Amyloidosis is a disease characterized by extracellular accumulation of amyloid protein in different organs and tissues. It may develop in localized (often with local production of light chain protein from mucosal lymphoid cells) or systemic form. Breast amyloidosis is very rare and usually occurs in patients with systemic amyloidosis (1). The cases described in the literature are those that presented with

micro-calcifications or mass-like lesions (1-4). Here, we would like to present an interesting case, who had history of breast surgery due to diagnosis of invasive ductal adenocarcinoma and was diagnosed with breast amyloidosis presented with a mass and with microcalcifications on the operation site.

\section{Case Presentation}

A 60-year-old woman who had a history of breast-conserving surgery with the diagnosis of invasive ductal carcinoma of the left breast 9 years ago presented to our hospital at the department of breast radiology for routine annual control. Physical examination was normal except for post-operative changes in the left breast. The patient had no complaints such as breast pain, nipple discharge or palpable mass. In the breast mammograms (IMS Giotto S.P.A., Italy) of left breast, fat necrosis areas due to

post-operative changes characterized by coarse calcifications were observed on CC (craniocaudal) projection in the retroareolar region (Figure 1). In the posterior of this area, a well-defined oval opacity accompanied by many round tight clustered micro- and macrocalcifications was observed which is deeply localized and not seen in the prior mammograms obtained 1 year ago (Figure 1). Breast Imaging Reporting and Data System (BI-RADS) was interpreted as category 4 (5) and histopathological evaluation was recommended because of interval development and breast cancer history of the patient. The area defined in mammography could not be visualized sonographically (Toshiba Aplio 500 Platinum, Japanese) due to the intense posterior acoustic shadowing of the fat necrosis areas. Pathological contrast enhancement was not detected in this area on the dynamic contrast enhanced magnetic resonance (MR) images (Figure 2). Ultrasound guided Tru-Cut biopsy was performed after marking the lesion with hook wire localization technique by mammography. 


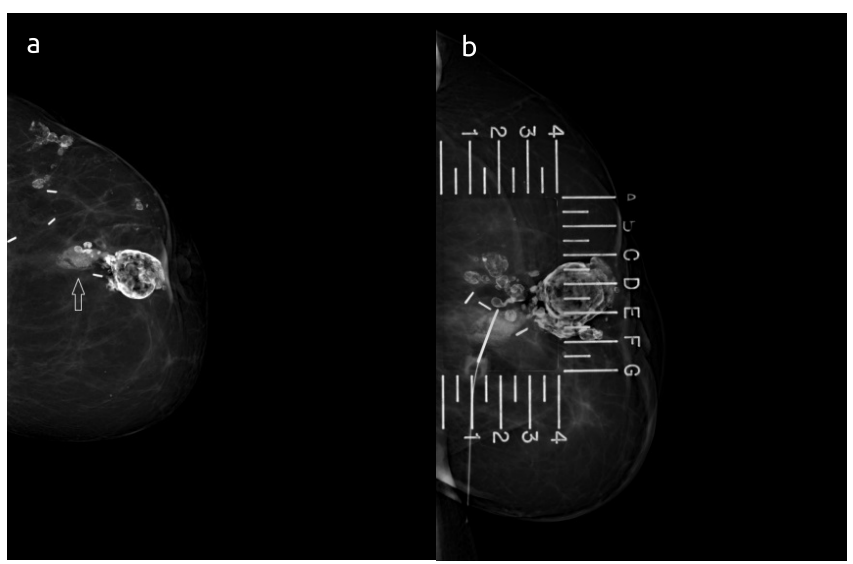

Figure 1 a, b. Mammogram of the left breast on CC projection reveals the oval opacity belongs to the amyloid accumulation (white arrow) accompanied by micro- and macro-calcifications (a). The mammogram obtained during the wire localization is demonstrated (b)
The material was fixed with $10 \%$ formaldehyde and formalin fixed paraffin blocks were cut to a thickness of 4 microns. Histochemical staining was performed with hematoxylin-eosin. Histopathological examination revealed homogeneous amorphous eosinophilic material accumulating around the terminal ductal lobular unit, stroma and vein walls (Figure 3). Subsequently, Congo red and crystal violet dyes were applied; and it was observed under the polarized light that areas with amorphous matter accumulation rendered 'apple green' reflections with Congo red (Figure 4). Amorphous material deposited areas showed positive reaction with crystal violet. Morphological and histochemical findings indicated the presence of amyloid accumulation. Clinical examination and laboratory tests for systemic amyloidosis did not show any supportive findings. The patient was diagnosed with localized breast amyloidosis and has been followed for about a year without any symptoms. Written informed consent was obtained from the patient.

\section{Discussion and Conclusion}

The breast amyloidosis was first described in 1973 and is extremely rare (6). It has been reported in the literature in the form of some case

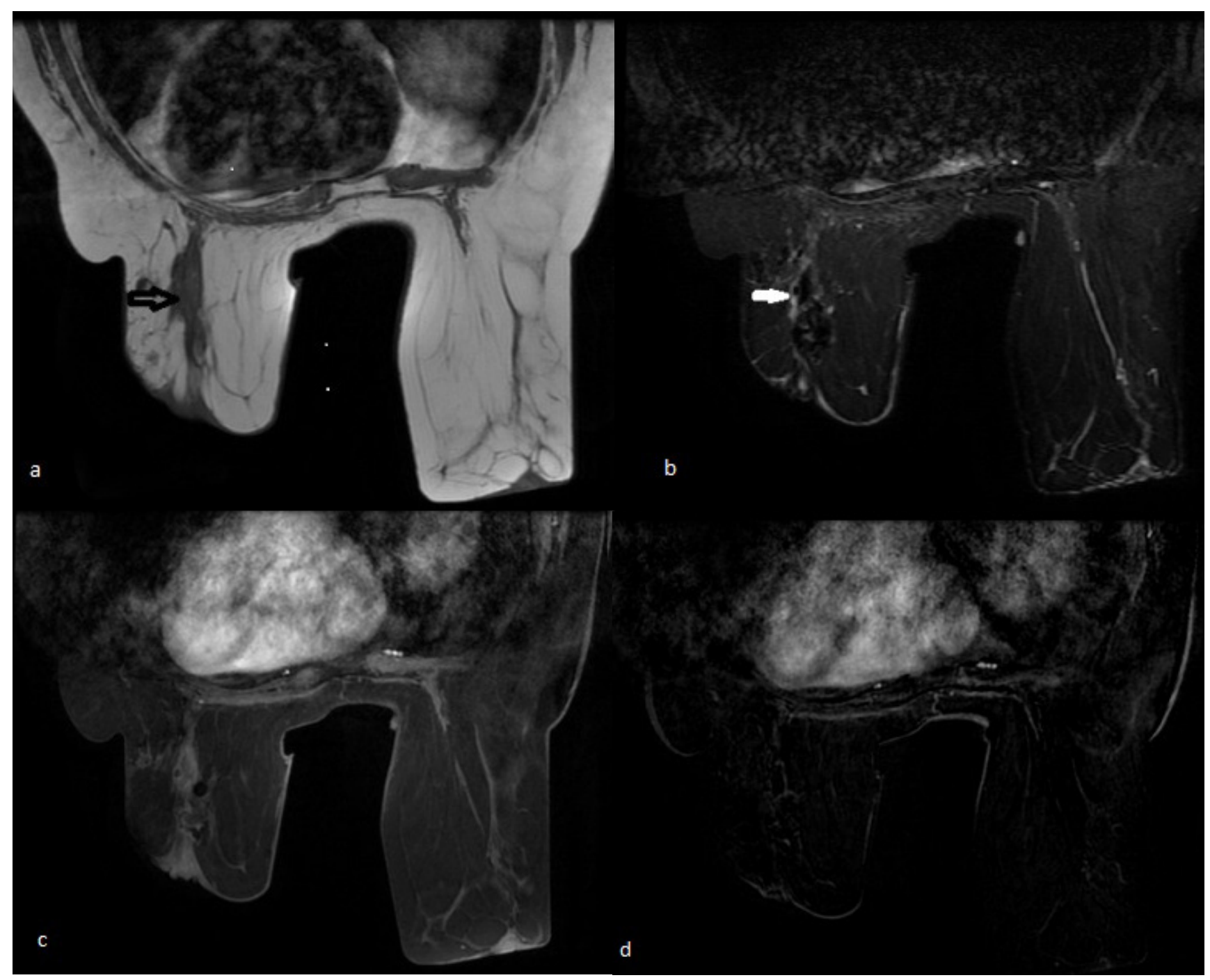

Figure 2. a-d. The lesion is observed as isointense both in axial fat suppressed T1 weighted (black arrow) (a) and T2 weighted (white arrow) images (b). No contrast enhancement was observed in post-contrast fat suppressed T1-weighted (c) and subtracted images (d) obtained 60 second after intravenous gadolinium injection 


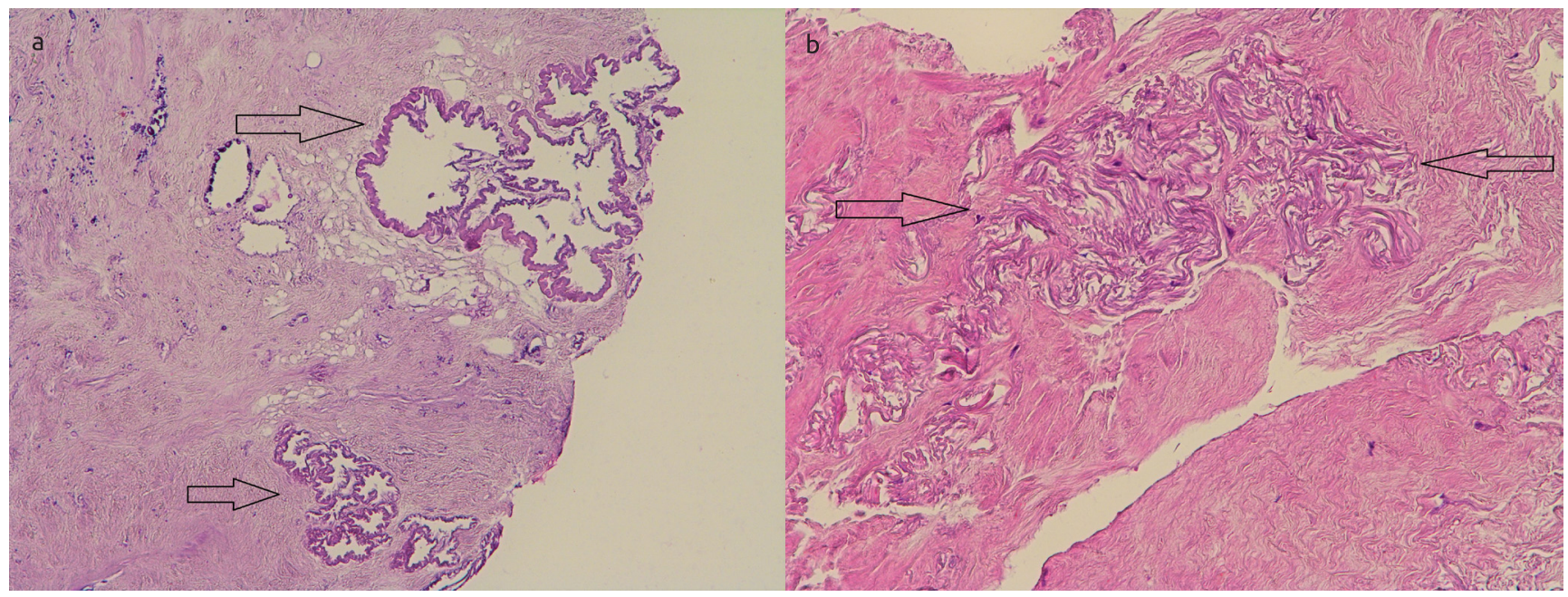

Figure 3. a, b. Amorphous eosinophilic amyloid deposition on terminal ductal lobular unit walls (a) and in the breast stroma (b) (H\&E x200)

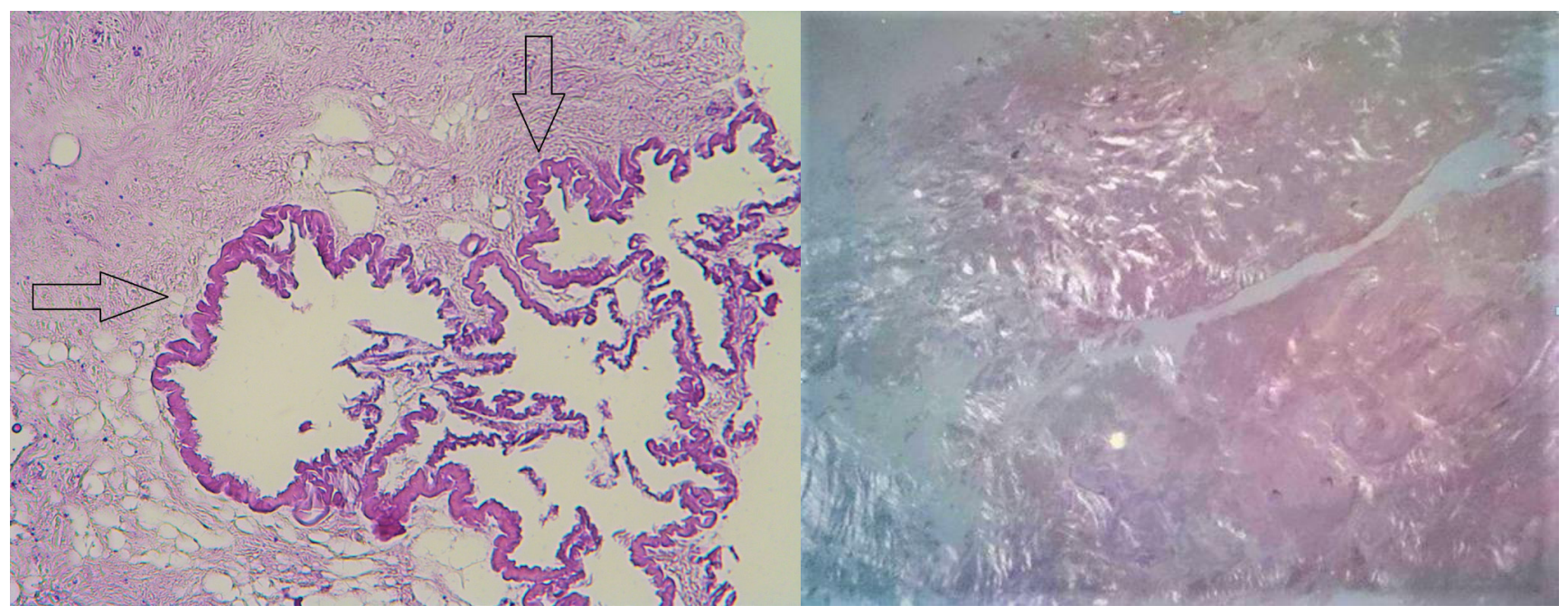

Figure 4. Amyloid deposition on terminal ductal lobular unit walls (H\&E, $x 400)$ (a) and Congo-red stained amyloid deposits in breast parenchyma (Congo-red x200)

reports or as a few case series. There has been no report of amyloidosis which developed in the operation site. MR findings of amyloidosis have also been reported as a single case study. From this point of view, we think that our case is valuable.

Amyloidosis is characterized by extracellular accumulation of amorphous fibrillar protein. They are grouped as systemic and localized according to accumulation area and as primer and secondary according to etiology. It is also classified according to its chemical structure as AA (amyloidosis), AL (light chain amyloidosis), familial amyloidosis (transtretine $[$ ATTR] $)(3,7,8)$. Breast amyloidosis frequently occurs in the late phase of systemic amyloidosis (9). Localized amyloidosis may also rarely be present $(1,2)$. In a published case series, $0.5 \%$ of patients who presented to the amyloid treatment center were found to have localized amyloidosis in the breast (1). Localized amyloidosis is frequently seen in postmenopausal women as in our case (2). In the literature, breast cancer has been reported to be associated with breast amyloidosis unlike our case $(2,7,10)$. Primary treatment method in primary breast amyloidosis is surgical excision. In the literature, unilateral mammography is recom- mended for 6 months after surgical excision, and it is recommended to follow the annual routine if there is no pathology except postoperative changes and scar tissue in mammography (2).

Radiological examination of breast amyloidosis may mimic malignant or benign lesions. Mammography findings have frequently been reported as solitary or multiple masses with or without microcalcifications $(2,11)$. Only micro-calcifications without mass formation have also been reported in some cases $(3,4)$. The amyloid protein accumulates in perivascular, periductal and intralobular areas in the breast. This causes foreign body reaction and the multinucleate giant cells accumulate in these areas. This protein has a calcium affinity, which is manifested by focal calcium accumulation in the breast tissue $(7,8,11)$. Calcium accumulation in perivascular and periductal areas are seen on mammography images as thin linear, branching, bar-shaped, pleomorphic or cluster-forming micro-calcifications and macrocalcifications (3, 4). In our case, the lesion was observed as a well-defined opacity accompanied by many round tight clustered micro- and macrocalcifications in the 
operation site and histopathological evaluation with pre-diagnosis of cancer recurrence was suggested. In the literature, sonographic findings are defined in a small number of cases and are non-specific. A hyperechoic or hypoechoic mass, an irregular shaped hypoechoic area or an isoechoic mass may be present on ultrasound imaging $(7,12,13)$. We could not visualize the lesion in our case because of the posterior intense shadowing of post-operative calcifications. So, the biopsy was performed by wire localization with the mammography guidance.

Magnetic resonance can be used as a problem-solving instrument in radiological breast assessment. Radiologists discuss the lesion by looking at the lesion morphology (it can be round, oval, lobulated or irregular), shape (smooth, irregular, spiculated), enhancement (mass or non-mass enhancement), T1 and T2 characteristics on MR. Irregular or spiculated margins, which are hypo-intense on T1-weighted images and moderate or low signal on T2 weighted fat sat images, have a high likelihood ratio for malignancy. In our case there is iso-intensity on T1 and T2 weighted images and no enhancement, which suggests it may be benign lesion. However, low grade DCIS (ductal carcinoma in-situ) rarely shows no enhancement on MR. Therefore, we always need to see the patient's mammography. If there are suspicious findings such as micro-calcifications, we should perform biopsy. In the case reported by O'brien et al. (14), amyloidosis was reported as hypo-intense areas in T1-weighted and hyperintense in T2-weighted images and non-enhanced areas in dynamic contrast-enhanced T1-weighted MR images.

In conclusion, primer localized amyloidosis is very rare in the breast. Since it can radiologically mimic malignancy, its radiological findings should be kept in mind and it should be included in the differential diagnosis.

Informed Consent: Written informed consent was obtained from patient who participated in this study.

Peer-review: Externally peer-reviewed.

Author Contributions: Concept - E.Y., N.U., Ü.T.P.; Design - E.Y., A.Y., İ.İ. Supervision A.Y., A.A., E.K.; Resources - E.Y., N.U., Ü.T.P., Ö.G.; Materials - E.Y., N.U., Ü.T.P., Ö.G.; Data Collection and/or Processing -- E.Y., N.U., Ü.T.P., Ö.G.; Analysis and/or Interpretation - E.Y., N.U., ÜT.P., Ö.G.; Literature Search - A.Y., A.A., E.K., İ.I.; Writing Manuscript - E.Y., N.U., Ü.T.P., Ö.G.; Critical Review A.Y., A.A., E.K., İ.İ.
Conflict of Interest: The authors have no conflicts of interest to declare.

Financial Disclosure: The authors declared that this study has received no financial support.

\section{References}

1. Charlot M, Seldin DC, O'hara C, Skinner M, Sanchorawala V. Localized amyloidosis of the breast: a case series. Amyloid 2011; 18: 72-75. (PMID: 21501022) [CrossRef]

2. Huerter ME, Hammadeh R, Zhou Q, Weisberg A, Riker AI. Primary amyloidosis of the breast presenting as a solitary nodule: case report and review of the literature. Ochsner J 2014; 14: 282-286. (PMID: 24940144)

3. Shim Y, Kim MJ, Ryu HS, Park SH. Primary breast amyloidosis presenting as microcalcifications only. Korean J Radiol 2013; 14: 723-726. (PMID: 24043964) [CrossRef]

4. Díaz-Bustamante T, Iríbar M, Vilarrasa A, Benito A, López-Ríos F. Primary amyloidosis of the breast presenting solely as microcalcifications. AJR Am J Roentgenol 2001; 177: 903-904. (PMID: 11566702) [CrossRef]

5. American College of Radiology. Breast imaging reporting and data system $^{\bullet}\left(\mathrm{BI}^{\left.-\mathrm{RADS}^{\circ}\right)}\right.$ ) Atlas. 5th ed. Reston, VA: American College of Radiology, 2013.

6. Fernandez BB, Hernandez FJ. Amyloid tumor of the breast. ArchPathol 1973; 95: 102-105. (PMID: 4683157)

7. Sabate JM, Clotet M, Torrubia S, Guerrero R, Pineda R, Lerma E, Capdevila E. Localize amyloidosis of the breast associated with invasive lobular carcinoma. Br J Radiol 2008; 81: e252-e254. (PMID: 18796554) [CrossRef]

8. Sabate JM, Clotet M, Gomez A, De LasHeras P, Torrubia S, Salinas T. Radiologic evaluation of uncommon inflammatory and reactive breast disorders. Radiographics 2005; 25: 411-424. (PMID: 15798059) [CrossRef]

9. Said SM, Reynolds C, Jimenez RE, Chen B, Vrana JA, Theis JD, Dogan A, Shah SS. Amyloidosis of the breast: predominantly AL type and overhalf hav econcurren tbreast hematologic disorders. Mod Pathol 2013; 26: 232-238. (PMID: 23018872) [CrossRef]

10. Munson-Bernardi BD, DePersia LA. Amyloidosis of thebreast coexisting with ductal carcinoma in situ. AJR Am J Roentgenol 2006; 186: 54-55. (PMID: 16357378) [CrossRef]

11. Röcken C, Kronsbein H, Sletten K, Roessner A, Böassler R. Amyloidosis of thebreast. Virchows Arch 2002; 440: 527-535. (PMID: 12021928) [CrossRef]

12. Tsuji W, Takeuchi E, Oka S, Yamashita T, Yotsumoto F. Localized primary amyloidosis of the breast: a case report and review of the literature. BMC Surg 2016; 16: 62. (PMID: 27624800) [CrossRef]

13. Eghtedari M, Dogan BE, Gilcrease M, Roberts J, Cook ED, Yang WT. Imaging and Pathologic Characteristics of Breast Amyloidosis. Breast J 2015; 21: 197-199. (PMID: 25585499) [CrossRef]

14. O'Brien J, Aherne S, McCormack O, Jeffers M, McInerney D. MRI features of bilateral amyloidosis of breast. Breast J 2013; 19: 338-339. (PMID: 23614366) [CrossRef] 